\title{
Predicting Adverse Pregnancy Outcomes During the Late First Trimester and Early Second Trimester Using the Uterine Artery Doppler
}

\author{
Dina Hassan Abdel Wahid, Mohammed Sabry Mahdy, Hala Elsayed Mowafy, Walid Abdullah Abdelsalam \\ Department of Obstetrics and Gynecology, Faculty of Medicine, Zagazig University, Egypt \\ Corresponding Author: Dina Hassan Abdel Wahid, Email: drdoodyhesham@gmail.com
}

\begin{abstract}
Background: The high resistance occurring in vessels of placenta pathologically can be assessed by impaired blood flow of uterine arteries of pregnant women. It has been proven that measuring of blood flow in the uterine artery in $1^{\text {st }}$ trimester is useful. Results from the second trimester, on the other hand, have proven to be more predictable.

Objective: The aim of the work was to predict fetal and maternal morbidity and mortality as a result of low placental blood flow. Subjects and Methods: This prospective study included a total of 127 pregnant women, attending for routine first trimester U/S scan at Department of Obstetrics and Gynecology, Zagazig University Hospitals. This study was conducted between April 2020 till December 2020.

Results: The mean Doppler Uterine artery resistance index (RI) was $0.587 \pm 0.22$ ranged from 0.31 to 1.21 and for pulsatility index (PI) $1.56 \pm 0.29$ ranged from 0.39 to 2.45 . The incidence rate of Fetal maternal adverse outcome was $22.8 \%$, distributed as $11.8 \%$ Maternal adverse outcome (most prevailing preeclampsia) and $15.7 \%$ Fetal adverse outcome (IUGR and preterm). There was statistically significant higher value of Doppler Uterine artery RI and Doppler Uterine artery PI of Adverse outcome compared to Favorable outcome women. Uterine artery PI was good marker to discriminate maternal fetal adverse outcome at late first to second trimester. While uterine artery RI was fair marker to discriminate maternal fetal adverse outcome at late first to second trimester.

Conclusions: It could be concluded that uterine artery PI was good marker while uterine artery RI was fair marker to discriminate maternal fetal adverse outcome at late first to second trimester.
\end{abstract}

Keywords: Adverse Outcome, Uterine Artery Doppler, Pregnancy.

\section{INTRODUCTION}

To ensure that the fetus receives the maximum amount of oxygen and nutrients during pregnancy, the trophoblasts of placenta go via the innermost third of the myometrium and the whole depth of the spiral arteries of the mother. In Preeclampsia women, no invasion occurs of trophoblasts through the muscle layer of uterus; hence, the spiral arteries and their cover of elastic muscles make the flow still to be difficult ${ }^{(\mathbf{1})}$.

The high resistance occurring in vessels of placenta pathologically can be assessed by impaired blood flow of uterine arteries of pregnant women, hence, helping clinicians identify pregnant women with preeclampsia. Doppler examinations in the first and second trimesters that showed atypical uterine arteries have also been connected to complications in perinatal life according to the recent studies ${ }^{(2)}$.

During systole, uterine artery flow velocity rises and falls rapidly in the non-pregnant condition, and the descending waveform has a notch in early diastole. Between 8 and 16 weeks of pregnancy, the uterine artery compliance increases significantly, and this trend maintained until 26 weeks of pregnancy, but to a lower level ${ }^{(3)}$.To identify existence of high resistance in uteroplacental vessels, many studies showed high parameters of PI or RI or diastolic notch persistence in uterine artery. Some studies have used only one cutoff number (e.g., RI > 0.58), whereas others have used percentage cutoff values to identify aberrant RI (e.g., $75^{\text {th }}, 90^{\text {th }}, 95^{\text {th }}$ ) (4).

Major Complications of pregnancy were detected cutoff to study PI of uterine artery in $1^{\text {st }}$ trimester, they reported that 30.8 percent had major sequalae ${ }^{(5)}$. This has resulted in the absence of any set guidelines for the gestational age at which testing should be performed, as well as the absence of any established criteria for abnormal uterine artery Doppler investigations. If the clinician has had sufficient training in this method, using a U/S being capable of both continuous and pulsed wave operation. Doppler tests on the uterine, arcuate, and sub placental arteries would be an acceptable strategy ${ }^{\left({ }^{(6)}\right.}$.

The reports appear to be useful in determining the flow rate of the uterine artery during the first trimester. The second trimester, on the other hand, has produced outcomes that are more consistent. It is acceptable to expect performance during 18-20 weeks of pregnancy. Evidence suggests that repeating the tests at 24-26 weeks may be beneficial in terms of gaining additional information ${ }^{(7)}$.

The aim of the current work was to predict fetal and maternal morbidity and mortality as a result of low placental blood flow.

\section{SUBJECTS AND METHODS}

This prospective study included a total of 127 pregnant women, attending for routine first trimester U/S scan at Department of Obstetrics and Gynecology, Zagazig University Hospitals. This study was conducted between April 2020 till December 2020.

\section{Ethical Consideration:}

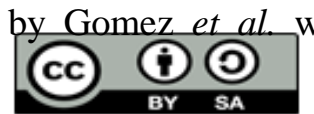

Received: 15/09/2021

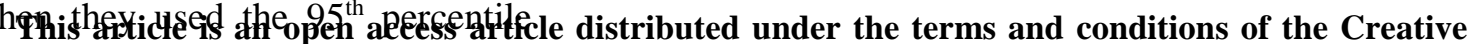
Commons Attribution (CC BY-SA) license (http://creativecommons.org/licenses/by/4.0/) 
All participants signed informed permission forms, and the study was given the green light by the Zagazig University Faculty of Medicine's Research Ethical Committee. The study was conducted in conformity with the World Medical Association's Code of Ethics for Human Research (Declaration of Helsinki).

Inclusion criteria: Normal fetus pregnancy with gestational age $11+0$ to $13+6$ weeks, High-risk pregnancies (hypothyroidism, diabetes mellitus, preeclampsia), Body mass index lower than $30 \mathrm{~kg} / \mathrm{m}^{2}$, nonsmoker, nonalcoholic or addict, not on treatment for chronic disease and not known to be hypertensive.

Exclusion criteria: Fetal malformation newborn, active bleeding or abortion, multiple pregnancy, uterine malformation or uterine myoma that could interfere with the volume measurements, and Failed attempts to obtain information from medical database records.

\section{All subjects were subjected to the following}

1. Careful and detailed history.

2. General and abdominal examination.

\section{Local examination:}

An examination of the uterus and the developing baby, A woman's uterus was palpated to see if it was laying in the middle of her belly, or if it was rotated to the left or right. The uterine wall was palpated to check for any abnormalities. If the uterine wall is irregular, it could mean one of two things: Pregnancy-related myomas (fibroid tumors) that grow and become uncomfortable, or an undiagnosed congenital condition such as a bicornuate uterus. Measuring the uterus's size before 18 weeks of pregnancy. Calculating the fundus's size at 18 weeks of pregnancy.

fetal palpation: the fetus's deception (oblique, transverse, or longitudinal).

The fetal presentation (breech presentation, cephalic or transverse presentation). Fetus back position (either fetus back is on right or left side of uterus). Estimation of the liquor content. Examining the motions of the fetus. An evaluation of the well-being of the fetus.

\section{Doppler Study:}

It was necessary to get a sagittal segment of the uterus and cervical canal. It was determined that the internal cervical OS was present, and the transducer was gently adjusted from side to side while color flow mapping was used to locate the uterine vessels. Pulsed wave Doppler was used to cover the whole vessel, with the sampling gate set at $2 \mathrm{~mm}$ to ensure complete coverage. An accumulative total of three successive uniform waveforms was recorded.

In the first trimester, The UA Doppler examination was carried out with the use of transabdominal ultrasound. A mid-sagittal segment of the uterus was taken, allowing for view of the cervical canal and internal cervical os, as well as other structures. A single measurement of the PI and resistance index (RI) of the right and left UAs was made electronically once and recorded, as was the presence and/or absence of the proto diastolic notch.

In the second trimester, obtaining a sagittal section of the cervix was accomplished with the use of a transvaginal transducer. Pulsed-wave Doppler was then used to produce waveforms of both UA and UA, which were compared to those obtained during the first trimester of pregnancy. The presence of a bilateral proto diastolic notch and/or a mean PI or RI value more than the 95th percentile were considered abnormal UA Doppler findings ${ }^{(7)}$.

\section{Follow-up:}

To acquire outcome data, patients were followed up until the end of their pregnancies and contacted after birth, and their medical records were analyzed to obtain the information. Whether or not patients experienced preeclampsia or other unfavorable pregnancy outcomes was the major outcome data collection point. Other secondary outcome data included: Preterm birth, Intrauterine fetal death / Stillbirth, Abruptio placenta, and Small for gestational age and fetal growth restriction.

\section{Statistical analysis:}

We used Statistical Package for Social Services version 24 to analyse the data (SPSS). Tables and graphs were used to display the data. We used mean SD and median (range) to convey continuous quantitative variables like age, as well as absolute frequencies (number) and relative frequencies (ratio) to express categorical qualitative variables like gender (percentage). A positive correlation shows how much those variables increase or drop in tandem, while a negative correlation shows how much one variable increases while the other decreases in correlation, Variables are related and depend on each other in a statistical relationship called a regression, which is used to determine the relationship between two or more variables. Statistically significant outcomes were defined as those with a significant probability of less than 0.05. There were two levels of statistical significance: highly significant (HS) for values below 0.05 , and non-significant for values beyond that threshold (NS).

\section{RESULTS}

Table 1 shows that the mean age was $26.61 \pm 3.43$ with range from 21 to 34 years. Clinical data of studied women, mean BMI was $25.83 \pm 2.2\left(\mathrm{~kg} / \mathrm{m}^{2}\right)$ ranged from 19.84 to 29.62 . Also, the same table reveals that the mean systolic blood pressure was $124 \pm 14.2$ $(\mathrm{mmHg})$ ranged from 105 to 170 ; diastolic blood pressure was $76 \pm 11.43 ;(\mathrm{mmHg})$ ranged from 60 to 110 . Doppler Uterine artery RI of studied women was $0.587 \pm 0.22$ ranged from 0.31 to 1.21 . Also, this table 
reveals that the mean uterine artery PI was $1.56 \pm 0.29$ ranged from 0.39 to 2.45 .

Table 2 displays that the incidence rate of Fetal maternal adverse outcome was $22.8 \%$, distributed as $11.8 \%$ Maternal adverse outcome and $15.7 \%$ Fetal adverse outcome. The most prevailing Maternal adverse outcome was preeclampsia. While the most prevailing fetal adverse outcome was IUGR, preterm.

Table 3 indicates that there was statistically significant deference between Adverse outcome and Favorable outcome women ( $\mathrm{p}=0.0001)$, regarding systolic blood pressure and diastolic blood pressure.

Table 4 indicates that there was statistically significant higher value of Doppler Uterine artery RI and Doppler Uterine artery PI of Adverse outcome compare to Favorable outcome women ( $p=0.0001)$.
Table 5 indicates that there was statistically significant higher value of Doppler Uterine artery PI of Adverse outcome compare to Favorable outcome women of IUGR, Preterm, Gest hypertension, Preeclampsia, Maternal adverse outcome, Fetal adverse outcome ( $\mathrm{p}<0.05)$.

Table 6, figure 1 illustrates sensitivity, specificity, Positive predictive value, Negative predictive value and accuracy obtained to Doppler Uterine artery PI, Doppler Uterine artery RI. At cut off value defined at above table. So, uterine artery PI was good marker to discriminate maternal fetal adverse outcome at late first to second trimester. While uterine artery RI was fair marker to discriminate maternal fetal adverse outcome at late first to second trimester.

Table (1): Age, clinical data, and uterine artery doppler at late first trimester and early second trimester of studied women.

\begin{tabular}{|l|c|}
\hline \multicolumn{1}{|c|}{ Characteristic } & Mean \pm SD \\
\hline Age $($ years $)$ & $26.61 \pm 3.43$ \\
\hline BMI $\left(\mathrm{kg} / \mathrm{m}^{2}\right)$ & $25.83 \pm 2.2$ \\
\hline SBP $(\mathrm{mmHg})$ & $124 \pm 14.2$ \\
\hline DBP $(\mathrm{mmHg})$ & $76 \pm 11.43$ \\
\hline Doppler parameter: Uterine artery RI & $0.587 \pm 0.22$ \\
\hline Uterine artery PI & $1.56 \pm 0.29$ \\
\hline
\end{tabular}

Table (2): Incidence rate of adverse outcomes of after follow up of studied women ( $\mathrm{n}=127)$.

\begin{tabular}{|l|c|c|c|c|}
\hline \multirow{2}{*}{} & \multicolumn{4}{|c|}{ Outcome } \\
\cline { 2 - 5 } & \multicolumn{2}{|c|}{ Adverse outcome } & \multicolumn{2}{c|}{ Favorable outcome } \\
\cline { 2 - 5 } & No. & $\mathbf{\%}$ & No. & \% \\
\hline Fetal maternal adverse outcome & 29 & 22.8 & 98 & 77.2 \\
\hline Maternal adverse outcome & 15 & 11.8 & 112 & 88.2 \\
\hline preeclampsia & 12 & 9.4 & 115 & 90.6 \\
\hline Gest hypertension & 2 & 1.6 & 125 & 98.4 \\
\hline Placental abruption & 1 & 0.8 & 126 & 99.2 \\
\hline Fetal adverse outcome & 20 & 15.7 & 107 & 92.3 \\
\hline IUGR & 9 & 7.1 & 118 & 92.9 \\
\hline preterm & 9 & 7.1 & 118 & 98.4 \\
\hline stillbirth & 2 & 1.6 & 125 & \\
\hline
\end{tabular}

Table (3): Comparison adverse outcomes and favorable outcome regard basic characters of studied women ( $\mathrm{n}=127)$.

\begin{tabular}{|l|c|c|c|c|}
\hline Characteristics & $\begin{array}{c}\text { Adverse outcome } \\
\mathbf{N = 2 9}\end{array}$ & $\begin{array}{c}\text { Favorable outcome } \\
\mathbf{N = 9 8}\end{array}$ & $\mathbf{t}$ & $\mathbf{P}$ \\
\hline Age $($ years $)$ & $27.34 \pm 3.36$ & $26.39 \pm 3.35$ & 1.307 & 0.194 \\
\hline BMI $\left(\mathrm{kg} / \mathrm{m}^{2}\right)$ & $25.84 \pm 2.04$ & $25.83 \pm 2.26$ & 0.032 & 0.975 \\
\hline SBP $(\mathrm{mmHg})$ & $135.58 \pm 19.66$ & $120.58 \pm 9.93$ & 3.962 & $0.0001^{*}$ \\
\hline DBP $(\mathrm{mmHg})$ & $85.52 \pm 15.41$ & $73.19 \pm 8.14$ & 4.138 & $0.0001^{*}$ \\
\hline
\end{tabular}

$(\mathrm{t})$ test of significant insignificant $\mathrm{p}>0.05 *$ significant $\mathrm{p}<0.05$

Table (4): Comparison adverse outcomes and favorable outcome regard uterine artery Doppler at late first trimester and early second trimester of studied women $(n=127)$.

\begin{tabular}{|l|c|c|r|r|}
\hline & $\begin{array}{c}\text { Adverse outcome } \\
\mathbf{N = 2 9}\end{array}$ & $\begin{array}{c}\text { Favorable outcome } \\
\mathbf{N = 9 8}\end{array}$ & \multicolumn{1}{c|}{ t } & \multicolumn{1}{c|}{ P } \\
\hline Uterine artery RI (Median) & 0.775 & 0.49 & $\mathrm{U}=3.94$ & 0.0001 \\
\hline Uterine artery PI (Mean \pm SD) & $1.88 \pm 0.359$ & $1.47 \pm 0.19$ & 5.930 & 0.0001 \\
\hline
\end{tabular}

(t ) test of significant $\mathrm{U}=$ Mann Whitnney u test *significant $\mathrm{p}<0.05$ 
Table (5): Comparison uterine artery Doppler pi for each adverse outcome at late first trimester and early second trimester of studied women (n.127).

\begin{tabular}{|c|c|c|c|c|}
\hline \multirow{2}{*}{$\begin{array}{c}\text { Adverse } \\
\text { outcome types }\end{array}$} & \multicolumn{2}{|c|}{ Uterine artery PI } & \multirow[t]{2}{*}{$\mathbf{t}$} & \multirow[t]{2}{*}{$\mathbf{P}$} \\
\hline & Adverse outcome & Favorable outcome & & \\
\hline $\begin{array}{l}\text { IUGR } \\
\text { Mean } \pm \text { SD }\end{array}$ & $\begin{array}{c}\mathrm{n} .9 \\
1.84 \pm 0.402\end{array}$ & $\begin{array}{c}\mathrm{n} .118 \\
1.54 \pm 0.275\end{array}$ & 2.9 & $0.003^{*}$ \\
\hline $\begin{array}{l}\text { Preterm } \\
\text { Mean } \pm \text { SD }\end{array}$ & $\begin{array}{c}\mathrm{n} .9 \\
1.766 \pm 0.331\end{array}$ & $\begin{array}{c}\mathrm{n} .118 \\
1.55 \pm 0.287\end{array}$ & 2.15 & $0.03^{*}$ \\
\hline $\begin{array}{l}\text { Stillbirth } \\
\text { Mean } \pm \text { SD }\end{array}$ & $\begin{array}{c}\mathrm{n} .2 \\
1.7675 \pm 0.385\end{array}$ & $\begin{array}{c}\mathrm{n} .125 \\
1.562 \pm 0.293\end{array}$ & 0.97 & 0.33 \\
\hline $\begin{array}{l}\text { Gest hypertension } \\
\text { Mean } \pm \text { SD }\end{array}$ & $\begin{array}{c}\mathrm{n} .2 \\
2.09 \pm 0.077 \\
\end{array}$ & $\begin{array}{c}\mathrm{n} .125 \\
1.556 \pm 0.288 \\
\end{array}$ & 2.6 & $0.01 *$ \\
\hline $\begin{array}{l}\text { Placental abruption } \\
\text { Mean } \pm \text { SD }\end{array}$ & $\begin{array}{l}\mathrm{n} .1 \\
1.6\end{array}$ & $\begin{array}{c}\mathrm{n} .126 \\
1.565 \pm 0.295\end{array}$ & 0.12 & 0.91 \\
\hline $\begin{array}{l}\text { Preeclampsia } \\
\text { Mean } \pm \text { SD }\end{array}$ & $\begin{array}{c}\mathrm{n} .12 \\
2.02 \pm 0.34\end{array}$ & $\begin{array}{c}\mathrm{n} .115 \\
1.514 \pm 0.237\end{array}$ & 7.1 & $0.0001 *$ \\
\hline $\begin{array}{ll}\text { Maternal } & \text { adverse } \\
\text { outcome } & \\
\text { Mean } \pm \text { SD } & \end{array}$ & $\begin{array}{c}\mathrm{n} .15 \\
2.02 \pm 0.34\end{array}$ & $\begin{array}{c}\mathrm{n} .112 \\
1.50 \pm 0.226\end{array}$ & 7.83 & $0.0001 *$ \\
\hline $\begin{array}{l}\text { Fetal adverse outcome } \\
\text { Mean } \pm \text { SD }\end{array}$ & $\begin{array}{c}\mathrm{n} .20 \\
1.79 \pm 0.351\end{array}$ & $\begin{array}{c}\mathrm{n} .107 \\
1.52 \pm 0.261\end{array}$ & 3.39 & $0.003^{*}$ \\
\hline
\end{tabular}

(t) test of significant insignificant $p>0.05 *$ significant $p<0.05$

Table (6): Performance of uterine artery PI, uterine artery RI to discriminate maternal fetal adverse outcome at late first to second trimester.

\begin{tabular}{|l|c|c|c|c|c|c|c|}
\hline \multirow{2}{*}{ Cut off level } & \multicolumn{2}{|c|}{$\begin{array}{c}\text { Maternal fetal } \\
\text { outcome }\end{array}$} & Sensitivity & Specificity & PPV & NPV & Accuracy \\
\cline { 2 - 4 } & Adverse & Normal & & & & \\
\hline $\begin{array}{l}\text { UA PI } \\
\geq 1.4925\end{array}$ & 24 & 39 & $82.76 \%$ & $60.20 \%$ & $38.10 \%$ & $92.19 \%$ & $65.35 \%$ \\
$<1.4925$ & 5 & 59 & & & & \\
\hline $\begin{array}{l}\text { UA RI } \\
\geq 0.5425\end{array}$ & 21 & 38 & $72.41 \%$ & $61.22 \%$ & $35.59 \%$ & $88.24 \%$ & $63.78 \%$ \\
$<0.5425$ & 8 & 60 & & & & & \\
\hline
\end{tabular}

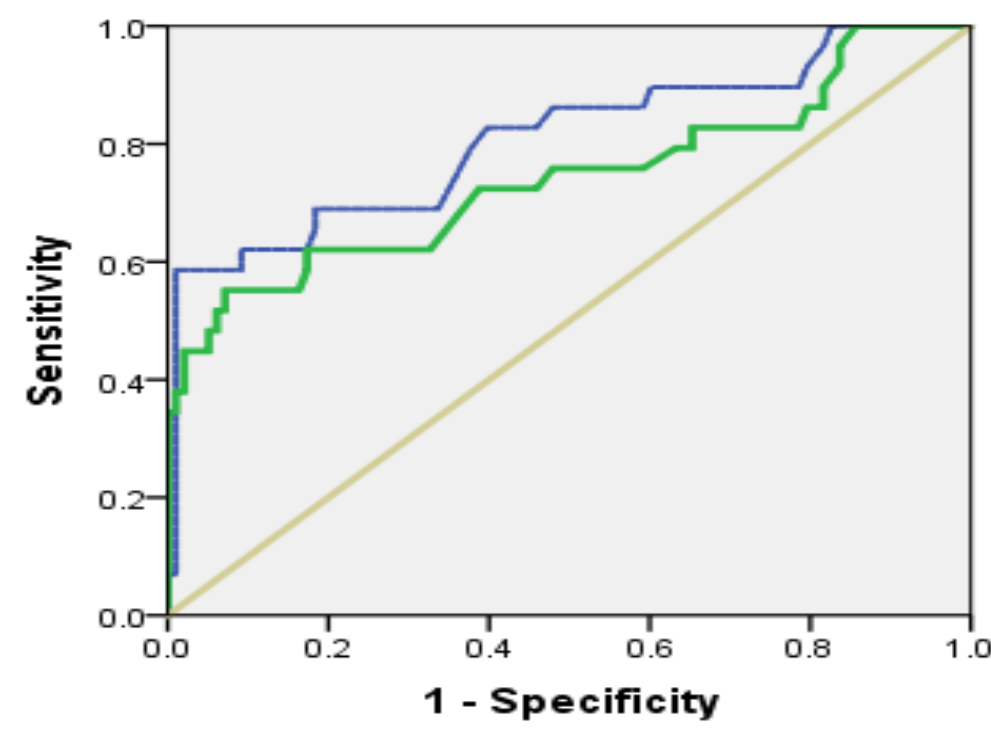

Uterine artery (PI)
Uterine artery (RI)

Reference Line

Figure (1): Shows ROC curve of uterine artery PI, uterine artery RI to discriminate maternal fetal adverse outcome at late first to second trimester. Area under curve (AUC) was 0.809 with (95\% CI 0.709-.911 p =0.0001), 0.741 with (95\% CI 0.621-.862 p =0.0001) respectively. 


\section{DISCUSSION}

If effective early identification of women at risk of having an unsatisfactory pregnancy result could be obtained, it is possible that prenatal care expenditures may be significantly decreased. Women with high-risk pregnancies should be closely monitored during their pregnancy, since this will allow for better management of these disorders in their future lives ${ }^{(8)}$. There is very little information available about the uteroplacental circulation Doppler pattern throughout the first and early second trimesters of pregnancy. Since routine nuchal translucency scanning and early second trimester anatomical assessments in our cohort and placental implantation were already scheduled for this time of gestation, a 14-20 week interval was chosen for the uterine Doppler study ${ }^{(9)}$.

Transabdominal uterine examination may encounter technical difficulties due to the uterus's small size, hence the full bladder approach is required for the Doppler examination at this time. As a result, a swollen bladder may change the flow of blood through small arteries ${ }^{(\mathbf{1 0})}$.

Since Doppler flow investigations of the uteroplacental circulation are simple, inexpensive, noninvasive, and may be performed early in pregnancy, it has been attempted to predict pre-eclampsia and a bad pregnancy outcome utilizing numerous maternal evaluation approaches in previous decades ${ }^{(11)}$. When the uterine artery is obstructed by an unfavorable pregnancy outcome and hypertension, the resistance to blood flow increases. More than 2.6 Systole/Diastole ratio in the third trimester, infant weight at delivery was lower than usual ${ }^{(\mathbf{1 0})}$.

In the present study, the mean age was $26.61 \pm 3.43$ with range from 21 to 34 years. This came in agreement with Gomez et al. ${ }^{(12)}$ who found that mean age was 30.5 years old. Also, Adefisan et al. ${ }^{(13)}$ found that mean age was 30.12 years old.

In the current study, mean BMI was $25.83 \pm 2.2$ with ranged from 19.84 to 29.62 , the mean of systolic blood pressure was $124 \pm 14.2$ with range from 105 to 170 and diastolic blood pressure, $76 \pm 11.43$; with range from 60 to 110. This came in agreement with Adefisan et al. ${ }^{(13)}$ who found that mean BMI was 26.39, SBP was 112.4, DBP was 68.9. Gomez et al. ${ }^{(\mathbf{1 2})}$ found that mean BMI was 23.9.

In the present study, the incidence rate of Fetal maternal adverse outcome was $22.8 \%$, distributed as $11.8 \%$ Maternal adverse outcome and $15.7 \%$ Fetal adverse outcome. The most prevailing Maternal adverse outcome was preeclampsia $(9.4 \%)$. While the most prevailing fetal adverse outcome was IUGR $(7.1 \%)$ and preterm $(7.1 \%)$.

This came in agreement with Gomez et al. ${ }^{(12)}$ who found that the most prevailing Maternal adverse outcome was preeclampsia. Adefisan et al. ${ }^{(13)}$ found that $20.0 \%$ had pre-eclampsia, $18.0 \%$ had pregnancyinduced hypertension without proteinuria, $26.0 \%$ had IUGR, 50.0\% had low birthweight neonates, and 6.0\% women experienced stillbirth. Fetal growth restriction (FGR) that develops in the absence of preeclampsia may also have its origin in defective placentation ${ }^{(14)}$.

In the present study, there was statistically significant higher value of Doppler Uterine artery RI and Doppler Uterine artery PI of Adverse outcome compare to favorable outcome women ( $p=0.0001)$.

According to Gomez et al. ${ }^{(\mathbf{1 2})}$, pregnancies that later developed any complication were found to have a significantly higher prevalence of bilateral notching compared with women who had a normal outcome: 58 percent versus 41 percent, respectively (P 0.05, Chisquare test), as well as a significantly higher mean PI: 2.04 versus 1.75 , respectively (P 0.05 , $t$-test).

Van den Elzen et al. $^{(15)}$ investigated 352 women at $12-13$ weeks of gestation and discovered that the group with a UtA-PI in the highest quartile had a fourfold and a twofold greater risk of developing hypertension and foetal growth restriction, respectively, after the birth of their child.

In the present study, When RI index was used to discriminate Maternal fetal adverse outcome at late first to second trimester. Sensitivity, Specificity, Positive predictive value, Negative predictive value $72.41 \%$, $61.22 \%, 35.59 \%, 88.24 \%$ respectively and when PI index was used, Sensitivity, Specificity, Positive predictive value, Negative predictive value $82.76 \%$, $60.2 \%, 38.1 \%, 92.19 \%$ respectively. So, uterine artery PI was good marker to discriminate maternal fetal adverse outcome at late first to second trimester. While uterine artery RI was fair marker to discriminate maternal fetal adverse outcome at late first to second trimester. While when they used to discriminate preeclampsia outcome at late first to second trimester both uterine artery PI, RI were good marker to discriminate preeclampsia outcome at late first to second trimester.

Cnossen et $\boldsymbol{a l} .{ }^{(16)}$ did a systemic review and by variable meta-analysis of 74 studies of pre-eclampsia found that abnormal uterine artery waveforms are better predictor of adverse pregnancy outcome (preeclampsia). When RI index was used, Sensitivity, Specificity, Positive predictive value, Negative predictive value $51 \%, 87 \%, 40 \%, 57 \%$ respectively and when PI index was used, Sensitivity, Specificity, Positive predictive value, Negative predictive value $39 \%, 78 \%, 18 \%, 78 \%$ respectively.

Gomez et al. ${ }^{(17)}$ discovered that when women's pregnancies ended in problems (preeclampsia, prenatal hypertension, and FGR), they had a greater mean PI and the persistence of a bilateral notch compared to women's pregnancies that ended in a healthy pregnancy. One of the most significant risk factors for unfavorable outcome was a persistently increased uterine artery pressure index (PI). Women still exhibited a significantly elevated risk of pregnancy problems even after their uterine artery PI returned to normal between the first and second trimesters. In women who had persistent bilateral notching, the risks were comparable. 


\section{CONCLUSION}

It could be concluded that uterine artery PI was good marker while uterine artery RI was fair marker to discriminate maternal fetal adverse outcome at late first to second trimester.

Financial support and sponsorship: Nil. Conflict of interest: Nil.

\section{REFERENCES}

1. Burton G, Jauniaux E (2017): The cytotrophoblastic shell and complications of pregnancy. Placenta, 60: 134139.

2. Salavati N, Smies M, Ganzevoort W et al. (2019) The Possible Role of Placental Morphometry in the Detection of Fetal Growth Restriction. Front Physiol., 9:1884-88.

3. Ismail A, Nassef A, El Desouky M (2019): Uterine Artery Doppler study and Serum B-Human Chorionic Gonadotropin as Predictors of Preeclampsia. The Egyptian Journal of Hospital Medicine, 76(7): 45914599.

4. Ravikumar M, Mallikarjuna M (2021): Correlation between abnormal Doppler indices and pregnancy outcome. International Journal of Clinical Obstetrics and Gynaecology, 5(1): 162-166.

5. Khong S, Kane S, Brennecke S et al. (2015): Firsttrimester uterine artery doppler analysis in the prediction of later pregnancy complications. Dis Markers, 15: Article ID 679730. https://doi.org/10.1155/2015/679730

6. Oloyede O, Iketubosin F (2013): Uterine artery Doppler study in second trimester of pregnancy. Pan Afr Med J., 15:87-92.

7. Mariana N, Chowdhury T, Choudhury T (2020): Uterine Artery Doppler Screening in 2nd Trimester of Pregnancy for Prediction of Pre-eclampsia and Fetal Growth Restriction. Journal of Advances in Medicine and Medical Research, 20: 7-22.

8. Melchiorre K, Wormald B, Leslie K et al. (2008): First trimester uterine artery Doppler indices in term and preterm pre-eclampsia. Ultrasound Obstet Gynecol., 32: 133-137.

9. Orabona R, Donzelli C, Falchetti $M$ et al. (2016) Placental histological patterns and uterine artery Doppler velocimetry in pregnancies complicated by early or late pre-eclampsia. Ultrasound in Obstetrics \& Gynecology, 47: 580- 585.

10. Polat I, Gedikbasi A, Kiyak H et al. (2015): Double notches:

association of uterine artery notch forms with pregnancy outcome and severity of preeclampsia. Hypertension in Pregnancy, 34: 90-101.

11. Payne B, Hutcheon J, Ansermino J et al. (2014): miniPIERS Study Working Group. A risk prediction model for the assessment and triage of women with hypertensive disorders of pregnancy in low-resourced settings: the miniPIERS (Pre-eclampsia Integrated Estimate of Risk) multi-country prospective cohort study. PLoS Med., 11: 1001-1005.

12. Gomez O, Martinez J, Figueras F et al. (2005): Uterine artery doppler at 11-14 weeks of gestation to screen for hypertensive disorders and associated complications in an unselected population. Ultrasound Obstet Gynecol., 26: 490-494.

13. Adefisan A, Akintayo A, Awoleke J et al. (2020): Role of second-trimester uterine artery Doppler indices in the prediction of adverse pregnancy outcomes in a low-risk population. International Journal of Gynecology \& Obstetrics, 151(2): 209-213.

14. Figueras F, Gratacós E (2014): Update on the diagnosis and classification of fetal growth restriction and proposal of a stage-based management protocol. Fetal Diagnosis and Therapy, 36(2): 86-98.

15. van den Elzen H, Cohen-Overbeek T, Grobbee D et al. (1995): Quartero RW, Wladimiroff JW. Early uterine artery Doppler velocimetry and the outcome of pregnancy in women aged 35 years and older. Ultrasound Obstet Gynecol., 5: 328-333.

16. Cnossen J S, Rachel K, Gerben R et al. (2008): van der Post, use of uterine artery Doppler ultrasonography to predict pre-eclampsia and intrauterine growth restriction: a systematic review and bivariable meta-analysis. Canadian Medical Association Journal, 178: 701-711.

17. Gomez O, Figueras F, Martinez J et al. (2006): Sequential changes in uterine artery blood flow pattern between the first and second trimesters of gestation in relation to pregnancy outcome. Ultrasound in Obstetrics and Gynecology, 28(6): 802-808. 